\title{
Associations Between Obesity and Multidimensional Frailty in Older Chinese People with Hypertension
}

This article was published in the following Dove Press journal:

Clinical Interventions in Aging

\author{
Xiaoyue Song $\mathbb{D}^{1,2}$ \\ Weihong Zhang $\mathbb{D}^{2}$ \\ Cynthia Hallensleben (D) \\ Anke Versluis (ID) \\ Rianne van der Kleij' \\ Zongliang Jiang ${ }^{2}$ \\ Niels H Chavannes (ID) \\ Robbert JJ Gobbens $\mathbb{D}^{3-5}$ \\ 'Department of Public Health and Primary \\ Care, Leiden University Medical Center, \\ Leiden 2333 ZD, The Netherlands; ${ }^{2}$ School \\ of Nursing, Zhengzhou University, \\ Zhengzhou, People's Republic of China; \\ ${ }^{3}$ Faculty of Health, Sports and Social Work, \\ Inholland University of Applied Sciences, \\ Amsterdam, The Netherlands; \\ ${ }^{4}$ Zonnehuisgroep Amstelland, Amstelveen, \\ The Netherlands; ${ }^{5}$ Department of Primary \\ and Interdisciplinary Care, Faculty of \\ Medicine and Health Sciences, University of \\ Antwerp, Antwerp, Belgium
}

Correspondence: Xiaoyue Song Department of Public Health and Primary Care, Leiden University Medical Center, Hippocratespad 2I, Leiden 2333 ZD, The Netherlands

$\mathrm{Tel}+3 \mid 6828 I 7080$

Email x.song@lumc.nl
Purpose: To investigate the prevalence of multidimensional frailty in older people with hypertension and to examine a possible relationship of general obesity and abdominal obesity to frailty in older people with hypertension.

Patients and Methods: A sample of 995 community-dwelling older people with hypertension, aged 65 years and older and living in Zhengzhou (China), completed the Tilburg Frailty Indicator (TFI), a validated self-report questionnaire for assessing multidimensional frailty. In addition, socio-demographic and lifestyle characteristics were assessed by self-report, and obesity was determined by measuring waist circumference and calculating the body mass index. Results: The prevalence of multidimensional frailty in this older population with hypertension was $46.5 \%$. Using multiple linear regression analysis, body mass index was significantly associated with physical frailty $(\mathrm{p}=0.001)$, and waist circumference was significantly positively associated with multidimensional frailty and all three frailty domains. Older age was positively associated with multidimensional frailty, physical frailty, and psychological frailty, while gender (woman) was positively associated with multidimensional, psychological, and social frailty. Furthermore, comorbid diseases and being without a partner were positively associated with multidimensional, physical, psychological, and social frailty. Of the lifestyle characteristics, drinking alcohol was positively associated with frailty domains.

Conclusion: Multidimensional frailty was highly prevalent among Chinese community-dwelling older people with hypertension. Abdominal obesity could be a concern in physical frailty, psychological frailty, and social frailty, while general obesity was concerning in relation to physical frailty. Keywords: older people, multidimensional frailty, obesity, hypertension

\section{Introduction}

Evidence suggests that frailty becomes more prevalent with increasing age and decreasing well-being in the older population. ${ }^{1,2}$ Frail older people show declines in physiological reserves and function across multiorgan systems, leading to increased morbidity and mortality. ${ }^{3}$ Currently, there is no unified definition of frailty, ${ }^{4-6}$ as some researchers define frailty based on biomedical indicators, ${ }^{4,5}$ while others define frailty more broadly. ${ }^{6,7}$ In the broader definition of frailty, besides physical frailty, aspects of both the psychological and social domains are included in frailty and collectively this model is referred to as 'multidimensional frailty'.

In this study, we adopted the definition of multidimensional frailty outlined by Gobbens et al. ${ }^{6}$ "Frailty is a dynamic state affecting an individual who experiences losses in one or more domains of human functioning (physical, psychological, social), which is 
caused by the influence of a range of variables and which increases the risk of adverse outcomes." 6

Chronic disease is an important determinant of multidimensional frailty, and hypertension is one of the most common chronic diseases among those aged 65 years and older. Hypertension is not only the main risk factor for cardiovascular diseases, but is also associated with multidimensional frailty. ${ }^{9-11}$ Multidimensional frailty is closely associated with a risk of falling and a lower quality of life. ${ }^{12,13}$ Greater awareness of the relationship between hypertension and frailty may help reduce adverse outcomes and decrease the prevalence of frailty. ${ }^{4,5}$

There has been a steady increase in the prevalence of obesity in older populations, and its negative impact on everyday life increases significantly with age. ${ }^{14,15}$ The prevalence of obesity in older populations is a growing concern, because as fat mass increases and muscle mass decreases, in addition to age-related declines in basal metabolic rate, muscle strength and physical activity. ${ }^{16}$ Obesity is also associated with other diseases, including diabetes mellitus, hypertension, coronary artery disease, and chronic heart failure. ${ }^{17}$ Commonly used measures of obesity include body mass index (BMI) and waist circumference (WC). The former is more closely related to general obesity and body weight, while the latter may more accurately reflect abdominal obesity and is more closely associated with metabolic disorders. There is evidence that obesity, especially in older people, increases the risk of physical inactivity and poor functional performance. ${ }^{16,18}$ Several earlier studies examined a possible association between obesity and physical frailty. ${ }^{19-21}$ Crow et al reported that in older adults, frailty was associated with a greater likelihood of high WC (both in dichotomized and continuous measurements). ${ }^{19}$ In addition, obesity is associated with risk of frailty and frailty syndrome in older women. $^{20,21}$ In other studies, obesity was found to be a predictive factor for physical frailty. ${ }^{22,23}$

However, studies on a possible link between obesity, fat distribution, and multidimensional frailty are scarce, and few studies have focused on the relationship between obesity and multidimensional frailty in older people with hypertension.

Obesity has also been associated with psychological problems, e.g., depression and anxiety, although the direction of the association has not yet been established. ${ }^{24,25}$ Moreover, obesity, and especially abdominal obesity, has a measurable impact on physical and mental health, healthrelated quality of life, and generates considerable direct and indirect costs. $^{26}$ Therefore, it is reasonable to hypothesize that obesity and multidimensional frailty may be linked.
In this study, our aims were (1) to investigate the prevalence of multidimensional frailty in communitydwelling older people with hypertension, and (2) to explore the relationship of general and abdominal obesity to multidimensional frailty in this specific population.

\section{Materials and Methods Subjects}

Between May 2016 and May 2017, a cross-sectional survey was performed in the community of Zhengzhou (China), which included community-dwelling older people $\geq 65$ years old diagnosed with hypertension by a physician (physician diagnosis reported by the participants). Hypertension is defined by a systolic pressure of $\geq 140$ or diastolic pressure of $\geq 90$. Individuals were excluded if they had an active malignancy, dementia or psychiatric disorders. A random multi-stage cluster sampling method was used to select the participants aged 65 and older from the Hangdong community, Nanguan community and Qinling community. In the first stage, the three communities (Hangdong, Nanguan and Qinling) in Zhengzhou were selected, including one in the east, one in the south, and one in the center of the city. The second stage involved the systematic random sampling of community centers from the three chosen communities, 20 in total. During the third stage, a list of residents by age and number of hypertension cases was compiled for each selected site (provided by the local residential committee), and a total of 1200 older people with hypertension were selected, of whom 995 completed the questionnaire. The response rate was $83 \%$.

\section{Ethics}

This study was approved by the Institutional Review Board of Zhengzhou University. All information was collected after written consent was obtained from all participants.

\section{Frailty}

Frailty was assessed by the Tilburg Frailty Indicator (TFI), a self-report questionnaire. ${ }^{6}$ The TFI is divided into three domains: a physical domain, a psychological domain, and a social domain. Physical frailty includes eight components: physical health, unexplained weight loss, difficulty in walking, lack of strength in hands, physical tiredness, difficulty in maintaining balance, poor hearing and poor vision. Psychological frailty consists of four components: cognition, depressive symptoms, anxiety, and coping. Social frailty includes three components: living alone, lack of social relations, and lack of social support. 
Eleven items in the TFI have two response categories ("yes" or "no"), while the remaining items (cognition, depressive symptoms, anxiety, lack of social relations) have three response categories ("yes", "no", or "sometimes"); these items were dichotomized. For a detailed description on scoring the TFI, including the dichotomization, we refer to a previous study. ${ }^{8}$ Each item was scored with 0 or 1 , with a maximum score for overall frailty of 15. For the physical, psychological, and social frailty domains, the maximum scores were 8,4 , and 3 , respectively. Total scores greater than or equal to 5 indicate frailty. The physical frailty cutoff is 3 , which means people who score 3 in that domain are physically frail. ${ }^{8}$ We used the Chinese version of the TFI, which was recently validated in community-dwelling older people. ${ }^{27}$ In the present study, the internal consistency and reliability of the Chinese version was acceptable (Cronbach's $\alpha=0.747$ ).

\section{Lifestyle Characteristics, Body Mass Index and Waist Circumference}

The included lifestyle characteristics were smoking (Do you smoke? ("yes" or "no")), drinking alcohol (Do you drink? ("yes" or "no")), physical activity (How often do you take exercise? (always $=$ more than 4 times a week; sometimes $=2-4$ times a week; hardly ever $=0-1$ times a week)), and breakfast (Do you have breakfast every day? ("yes" or "no")). In addition, body mass index (BMI) and waist circumference (WC) were assessed. Weight, height, and WC were measured in each subject. These measurements were carried out by trained nursing postgraduates using electronic scales (model SH-10XD) and flexible, inelastic belt-type tapes, respectively. Measurements were taken twice. Mean values of the two measurements were used for the analyses. BMI was calculated as the weight in $\mathrm{kg}$ divided by the square of the height in meters. Subjects were initially categorized into four BMI groups according to the World Health Organization guideline for Asians: underweight $\left(<18.5 \mathrm{~kg} / \mathrm{m}^{2}\right)$, normal weight (from 18.5 to $22.9 \mathrm{~kg} / \mathrm{m}^{2}$ ), overweight (from 23 to $24.9 \mathrm{~kg} / \mathrm{m}^{2}$ ), and general obesity (over $25 \mathrm{~kg} / \mathrm{m}^{2}$ ). ${ }^{28}$ Abdominal obesity was defined as a $\mathrm{WC} \geq 90 \mathrm{~cm}$ in men and $\geq 80 \mathrm{~cm}$ in women. $^{29,30}$

\section{Socio-Demographic Characteristics and Disease}

The socio-demographic characteristics measured were: age, gender, marital status (two categories: married/with partner or other (unmarried, divorced, or widowed)), educational level (five categories: no schooling, primary school, middle school, high school, or university), and monthly income (yuan) (four categories: <1000; 1000 1999; 2000 2999; 3000 ). Five categories of disease, including four chronic diseases common in the Chinese population, were assessed using self-report: cardiovascular disease, cancer, chronic respiratory diseases, diabetes, or other diseases. ${ }^{31}$ The total number of chronic diseases was used in our analyses.

\section{Data Analysis}

Descriptive statistics were used to determine the characteristics of participants $(\mathrm{N}=995)$. The data are presented as the mean $\pm \mathrm{SD}$ and frequencies (percentages). Because the underweight group was small $(n=5)$, this group is only included in the descriptive statistics and a single analysis (see below). Bivariate analyses were conducted to determine the associations between demographic characteristics, lifestyle characteristics, comorbid diseases, BMI, WC, multidimensional frailty, and three frailty domains (physical, psychological, social). The Chi-square test was used to compare the prevalence of frailty for categorical variables. One-way ANOVA analyses were selected to compare the detailed frailty scores (physical frailty, psychological frailty and social frailty) in categorical groups. We then carried out multiple linear regression analyses with the goal of determining the individual effects of BMI and WC on multidimensional frailty and its three domains, adjusted for other variables in the model (socio-demographic characteristics, lifestyle characteristics). All statistical analyses were performed with SPSS 20.0 (SPSS Inc., Chicago, IL, U.S.A.). The statistical significance level was set at $p<0.05$.

\section{Results}

\section{Participant Characteristics}

The characteristics of participants by BMI and WC category are shown in (Table 1). A total of 995 subjects were recruited, $47.7 \%$ men and $52.3 \%$ were women. Mean age was $75.1( \pm 7.38)$ and $82.0 \%$ were married or with partners. General obesity was found in 99 participants $(9.9 \%)$ and 492 participants (49.4\%) had abdominal obesity. The prevalence of multidimensional frailty and physical frailty was $46.5 \%$ and $45.1 \%$, respectively. (Table 1) also presents the demographic and lifestyle characteristics based on the BMI and $\mathrm{WC}$ of the participants. 
Table I Characteristics of Participants by Categories of BMI and WC (N=995)

\begin{tabular}{|c|c|c|c|c|c|c|}
\hline \multirow[t]{2}{*}{ Variables } & \multicolumn{4}{|l|}{ BMI n (\%) } & \multicolumn{2}{|l|}{ WC (cm) n (\%) } \\
\hline & $\begin{array}{l}\text { Underweight } \\
5(0.5)\end{array}$ & $\begin{array}{l}\text { Normal } 524 \\
(52.7)\end{array}$ & $\begin{array}{l}\text { Overweight } \\
367 \text { (36.9) }\end{array}$ & $\begin{array}{l}\text { Obese } 99 \\
(9.9 \%)\end{array}$ & $\begin{array}{l}<90(M)<80(W) \\
492(49.4)\end{array}$ & $\begin{array}{l}\geq 90(M) \geq 80(W) \\
503(50.6)\end{array}$ \\
\hline \multicolumn{7}{|c|}{ Socio-Demographic Characteristics } \\
\hline \multicolumn{7}{|l|}{ Age } \\
\hline $65-74$ & I (20.0) & $304(58.0)$ & $159(43.3)$ & $47(47.5)$ & $246(48.9)$ & $265(53.9)$ \\
\hline $75-84$ & $2(40.0)$ & $178(34.0)$ & $142(38.7)$ & $34(34.3)$ & $172(34.2)$ & $184(37.4)$ \\
\hline$\geq 85$ & $2(40.0)$ & $42(8.0)$ & $66(18.0)$ & $18(18.2)$ & $85(16.9)$ & $43(8.7)$ \\
\hline \multicolumn{7}{|l|}{ Gender } \\
\hline Men & $4(80.0)$ & $299(57.1)$ & $130(35.4)$ & $39(39.4)$ & $232(46.1)$ & $240(48.8)$ \\
\hline Women & I (20.0) & $225(42.9)$ & $237(64.6)$ & $60(60.6)$ & $27 \mid(53.9)$ & $252(5 \mid .2)$ \\
\hline \multicolumn{7}{|l|}{ Marital Status } \\
\hline Married/With partner & $4(80.0)$ & $465(87.9)$ & $279(76.0)$ & $72(72.7)$ & $394(78.3)$ & $422(85.8)$ \\
\hline Others & I (20.0) & $65(12.1)$ & $88(24.0)$ & $27(27.3)$ & $109(21.7)$ & $70(14.2)$ \\
\hline \multicolumn{7}{|c|}{ Monthly Income in Yuan (Dollar) } \\
\hline$<1000(<\$ 143)$ & I (20.0) & $90(17.0)$ & $61(16.6)$ & $17(17.2)$ & $113(22.5)$ & $55(11.2)$ \\
\hline $1000-1999(\$ 143-\$ 286)$ & I (20.0) & $219(4 I .4)$ & $130(35.4)$ & $49(49.5)$ & $195(38.8)$ & $133(27.0)$ \\
\hline $2000-2999(\$ 286-\$ 429)$ & $3(60.0)$ & $106(20.0)$ & $125(34.1)$ & $29(29.3)$ & $137(27.2)$ & $160(32.5)$ \\
\hline$\geq 3000(\geq \$ 429)$ & $0(0.0)$ & $114(21.6)$ & $51(13.9)$ & $4(4.0)$ & $58(11.5)$ & $144(29.3)$ \\
\hline \multicolumn{7}{|l|}{ Educational Level } \\
\hline No schooling & $0(0.0)$ & $15(2.9)$ & $61(16.6)$ & $32(32.3)$ & $77(15.3)$ & $31(6.3)$ \\
\hline Primary school & $2(40.0)$ & $34(6.5)$ & $138(37.6)$ & $45(45.5)$ & $133(27.2)$ & $86(17.5)$ \\
\hline Middle school & I (20.0) & $225(42.9)$ & $155(42.2)$ & $20(20.2)$ & $203(40.4)$ & $198(40.2)$ \\
\hline High school & $2(40.0)$ & $166(31.7)$ & $9(2.5)$ & $0(0.0)$ & $66(13.1)$ & $111(22.6)$ \\
\hline University & $0(0.0)$ & $84(15.9)$ & $4(1.1)$ & $2(2.0)$ & $24(4.8)$ & $66(13.4)$ \\
\hline \multicolumn{7}{|l|}{ Comorbid Diseases } \\
\hline 0 & $2(40.0)$ & $117(22.3)$ & $78(21.3)$ & $31(31.3)$ & $|4|(28.0)$ & $87(17.7)$ \\
\hline I & $2(40.0)$ & $|4|(26.9)$ & $110(30.0)$ & $18(18.2)$ & $146(29.0)$ & $125(25.4)$ \\
\hline$\geq 2$ & I (20.0) & $266(50.8)$ & $179(48.7)$ & $50(50.5)$ & $216(43.0)$ & $280(56.9)$ \\
\hline \multicolumn{7}{|l|}{ Lifestyle Characteristics } \\
\hline \multicolumn{7}{|l|}{ Smoking } \\
\hline Yes & $4(80.0)$ & $178(34.0)$ & $120(32.7)$ & $27(27.3)$ & $183(36.4)$ & $143(29.1)$ \\
\hline No & I (20.0) & $346(66.0)$ & $247(67.3)$ & $72(72.7)$ & $320(63.6)$ & 349 (70.9) \\
\hline \multicolumn{7}{|l|}{ Drinking Alcohol } \\
\hline Yes & I (20.0) & $142(27.1)$ & $126(34.3)$ & $49(49.4)$ & $185(36.8)$ & $133(27.0)$ \\
\hline No & $4(80.0)$ & $382(72.9)$ & $24 \mid(65.7)$ & $50(50.6)$ & $318(63.2)$ & $359(73.0)$ \\
\hline \multicolumn{7}{|l|}{ Physical Activity } \\
\hline Always & $4(80.0)$ & $25 I(47.9)$ & $182(49.6)$ & $47(47.5)$ & $211(4 I .9)$ & $273(55.5)$ \\
\hline Sometimes & I (20.0) & $148(28.2)$ & $111(30.2)$ & $35(35.4)$ & $198(39.4)$ & $97(19.7)$ \\
\hline Hardly ever & $0(0.0)$ & 125 & $74(20.2)$ & $17(17.1)$ & $94(18.7)$ & $122(24.8)$ \\
\hline \multicolumn{7}{|l|}{ Breakfast } \\
\hline Yes & $5(100.0)$ & $508(96.9)$ & $359(97.8)$ & $96(97.0)$ & $478(95.0)$ & $490(99.6)$ \\
\hline No & $0(0.0)$ & $16(3.1)$ & $8(2.2)$ & $3(3.0)$ & $25(5.0)$ & $2(0.4)$ \\
\hline
\end{tabular}

(Continued) 
Table I (Continued).

\begin{tabular}{|c|c|c|c|c|c|c|}
\hline \multirow[t]{2}{*}{ Variables } & \multicolumn{4}{|l|}{ BMI n (\%) } & \multicolumn{2}{|l|}{ WC (cm) n (\%) } \\
\hline & $\begin{array}{l}\text { Underweight } \\
5(0.5)\end{array}$ & $\begin{array}{l}\text { Normal } 524 \\
(52.7)\end{array}$ & $\begin{array}{l}\text { Overweight } \\
367(36.9)\end{array}$ & $\begin{array}{l}\text { Obese } 99 \\
(9.9 \%)\end{array}$ & $\begin{array}{l}<90(M)<80(W) \\
492(49.4)\end{array}$ & $\begin{array}{l}\geq 90(M) \geq 80(W) \\
503(50.6)\end{array}$ \\
\hline \multicolumn{7}{|l|}{ Frailty } \\
\hline \multicolumn{7}{|l|}{ Multidimensional Frailty } \\
\hline Yes & I (20.0) & $189(36.1)$ & $211(57.5)$ & $59(59.6)$ & $302(60.0)$ & $161(32.7)$ \\
\hline No & $4(80.0)$ & $335(63.9)$ & $156(42.5)$ & $40(40.4)$ & $201(40.0)$ & 331 (67.3) \\
\hline \multicolumn{7}{|l|}{ Physical Frailty } \\
\hline Yes & $3(60.0)$ & $106(20.2)$ & $120(32.7)$ & $38(38.4)$ & $173(34.4)$ & $94(19.1)$ \\
\hline No & $2(40.0)$ & $418(79.8)$ & $247(67.3)$ & $61(61.6)$ & $330(65.6)$ & $398(80.9)$ \\
\hline
\end{tabular}

Abbreviations: BMI, body mass index; WC, waist circumference.

\section{Associations Between BMI, WC, and Frailty}

(Table 2) presents the associations between sociodemographic characteristics, disease, lifestyle characteristics, BMI, WC and frailty. In terms of BMI category, subjects in the general obesity group had higher multidimensional frailty scores than subjects in the overweight group and the underweight/normal group (5.82 \pm 3.55 vs. $5.38 \pm 3.31$ vs. $4.05 \pm 3.17, \mathrm{p}<0.001)$. Regarding categories of WC, obese subjects (men with WC $>94 \mathrm{~cm}$, and women with $\mathrm{WC}>$ $80 \mathrm{~cm})$ had higher frailty scores than other subjects $(5.67 \pm$ 3.49 vs. $3.74 \pm 2.86, \mathrm{p}<0.001)$.

\section{Regression Analyses}

Multiple linear regression analyses revealed that general obesity was only significantly positively associated with physical frailty ( $\mathrm{p}=0.018$ ), adjusted for all sociodemographic and lifestyle characteristics in the model. Abdominal obesity was significantly positively associated with all four frailty variables (for multidimensional frailty, $\mathrm{p}<0.001$, for physical frailty, $\mathrm{p}=0.001$, for psychological frailty, $\mathrm{p}<0.001$, social frailty, $\mathrm{p}<0.001$ ), adjusted for all variables in the model (see Table 3 ).

The regression analyses also showed that older age was significantly positively associated with multidimensional frailty, physical frailty, and psychological frailty, while gender (women) was positively associated with multidimensional, psychological and social frailty. High monthly income was negatively associated with social frailty. Comorbid diseases and an unmarried or without partner status were significantly positively associated with all frailty domains.
It is worth noting that among the lifestyle characteristics, drinking alcohol and eating breakfast were the only domains that significantly associated with three or two frailty variables, respectively. The $R^{2}$ values demonstrated that the variables in the model together explained a significant portion of the variance of multidimensional frailty (physical frailty, psychological frailty, and social frailty) (see Table 3).

\section{Discussion}

Of the participants in our study, almost half (46.5\%) showed multidimensional frailty. This outcome is higher than that reported by Dong et al. ${ }^{32}$ (13.1\%), a similar study but conducted in Jinan, a socioeconomically developed city in Eastern China, whereas our study in Zhengzhou, a stilldeveloping city in central China, included older people with a lower educational level and lower monthly income compared to Jinan. Previous studies have shown that both of these important socioeconomic factors are associated with higher multidimensional frailty scores. ${ }^{33,34}$ In our study, $45.1 \%$ of the participants experienced physical frailty, a prevalence figure much higher than that found in earlier studies conducted in China (12.4\%). ${ }^{32,33}$ One possible explanation for the difference in findings was that our participants were older people ( $\geq 65$ years old) with hypertension, while the participants in the other studies were below 65 years of age and with or without chronic diseases. Furthermore, the prevalence figures for physical frailty $(45.1 \%)$ and multidimensional frailty $(46.5 \%)$ were very similar and in line with our previous study in the Netherlands. ${ }^{8}$

Our results indicate that both general obesity and abdominal obesity are positively associated with physical frailty, a finding consistent with a previous report by Garcia- 
Table 2 Associations Between Socio-Demographic Characteristics, Diseases, Lifestyle Characteristics, BMI, WC and Frailty (N=990)

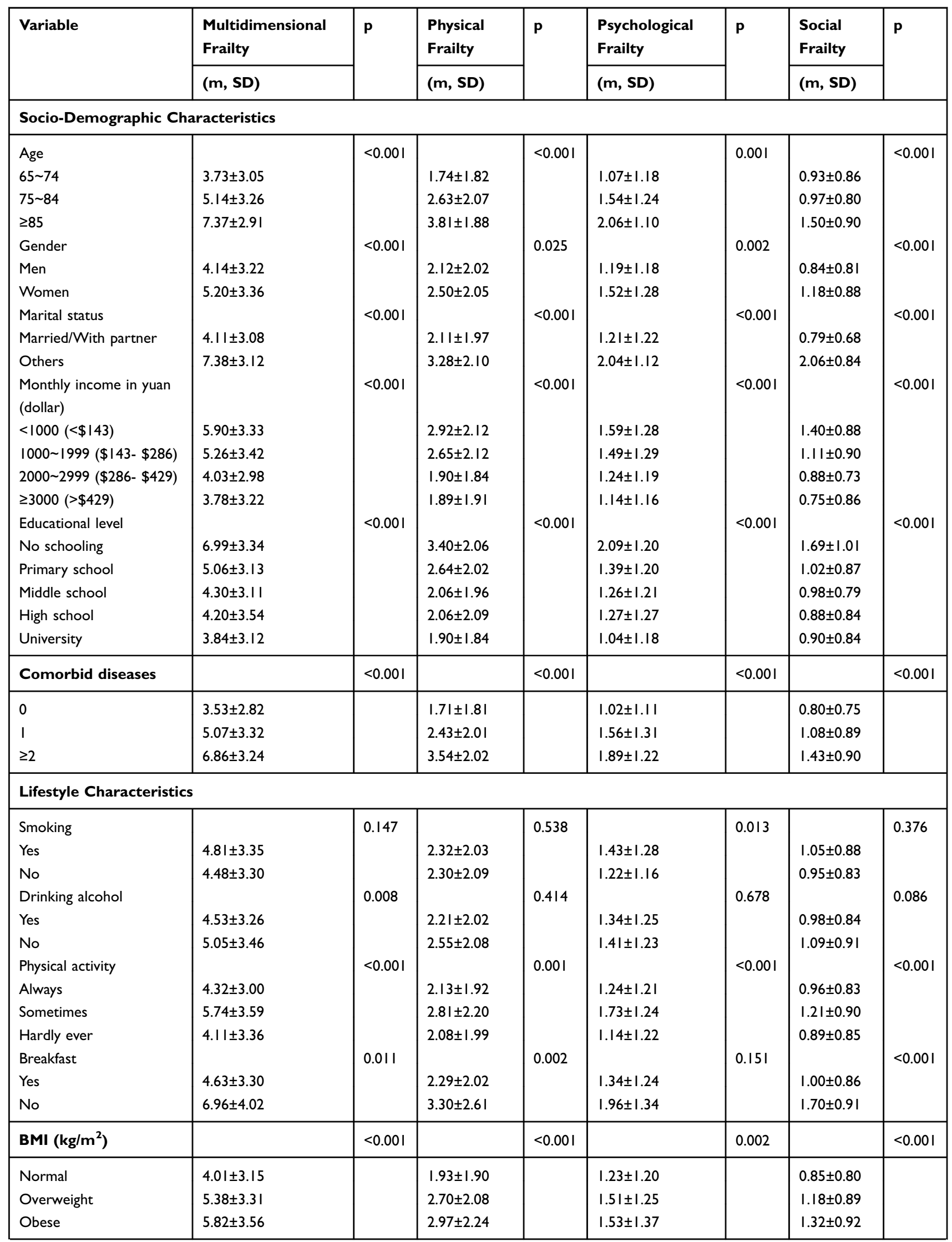

(Continued) 
Table 2 (Continued).

\begin{tabular}{|c|c|c|c|c|c|c|c|c|}
\hline \multirow[t]{2}{*}{ Variable } & $\begin{array}{l}\text { Multidimensional } \\
\text { Frailty }\end{array}$ & \multirow[t]{2}{*}{$\mathbf{p}$} & $\begin{array}{l}\text { Physical } \\
\text { Frailty }\end{array}$ & \multirow[t]{2}{*}{$\mathbf{p}$} & $\begin{array}{l}\text { Psychological } \\
\text { Frailty }\end{array}$ & \multirow[t]{2}{*}{$\mathbf{p}$} & $\begin{array}{l}\text { Social } \\
\text { Frailty }\end{array}$ & \multirow[t]{2}{*}{$\mathbf{p}$} \\
\hline & $(\mathrm{m}, \mathrm{SD})$ & & $(\mathrm{m}, \mathrm{SD})$ & & $(\mathrm{m}, \mathrm{SD})$ & & $(m, S D)$ & \\
\hline WC (cm) & & $<0.001$ & & $<0.001$ & & $<0.001$ & & $<0.001$ \\
\hline $\begin{array}{l}>90 \text { men }>80 \text { women } \\
\leq 90 \text { men } \leq 80 \text { women }\end{array}$ & $\begin{array}{l}5.65 \pm 3.49 \\
3.73 \pm 2.86\end{array}$ & & $\begin{array}{l}2.75 \pm 2.11 \\
1.87 \pm 1.88\end{array}$ & & $\begin{array}{l}1.64 \pm 1.29 \\
1.07 \pm 1.12\end{array}$ & & $\begin{array}{l}1.25 \pm 0.92 \\
0.78 \pm 0.73\end{array}$ & \\
\hline
\end{tabular}

Abbreviations: BMI, body mass index; WC, waist circumference.

Table 3 Effects of the Socio-Demographic and Lifestyle Characteristics on Frailty: Multiple Linear Regression Analyses ( $N=990)$

\begin{tabular}{|c|c|c|c|c|c|c|c|c|c|c|c|c|}
\hline & \multicolumn{3}{|c|}{ Multidimensional Frailty } & \multicolumn{3}{|c|}{ Physical Frailty } & \multicolumn{3}{|c|}{ Psychological Frailty } & \multicolumn{3}{|c|}{ Social Frailty } \\
\hline & B & SE & $\mathbf{p}$ & B & SE & $\mathbf{P}$ & B & SE & $\mathbf{P}$ & B & SE & $\mathbf{p}$ \\
\hline \multicolumn{13}{|c|}{ Socio-Demographic Characteristics } \\
\hline Age & 0.132 & 0.012 & $<0.001$ & 0.090 & 0.008 & $<0.001$ & 0.039 & 0.005 & $<0.001$ & 0.004 & 0.003 & 0.213 \\
\hline Gender & 0.486 & 0.179 & 0.007 & 0.332 & 0.159 & 0.037 & 0.221 & 0.101 & 0.029 & 0.269 & 0.062 & $<0.001$ \\
\hline Marital status & 5.837 & 1.502 & $<0.001$ & 0.395 & 0.151 & 0.009 & 0.468 & 0.096 & $<0.001$ & 1.034 & 0.059 & $<0.001$ \\
\hline Monthly income & -0.334 & 0.162 & 0.040 & -0.118 & 0.109 & 0.275 & 0.016 & 0.069 & 0.818 & -0.138 & 0.042 & 0.001 \\
\hline Education level & 0.174 & 0.122 & 0.154 & 0.103 & 0.082 & 0.206 & -0.044 & 0.052 & 0.397 & 0.061 & 0.032 & 0.056 \\
\hline Comorbid diseases & 1.400 & 0.105 & $<0.001$ & 0.808 & 0.070 & $<0.001$ & 0.358 & 0.045 & $<0.001$ & 0.211 & 0.027 & $<0.001$ \\
\hline \multicolumn{13}{|c|}{ Lifestyle Characteristics } \\
\hline Smoking & -0.251 & 0.206 & 0.223 & 0.197 & 0.159 & 0.215 & -0.089 & 0.101 & 0.380 & 0.043 & 0.062 & 0.488 \\
\hline Drinking alcohol & 0.502 & 0.207 & 0.016 & 0.396 & 0.148 & 0.008 & 0.234 & 0.094 & 0.013 & 0.125 & 0.057 & 0.030 \\
\hline Physical activity & 0.105 & 0.104 & 0.313 & 0.064 & 0.070 & 0.360 & 0.006 & 0.044 & 0.898 & 0.004 & 0.027 & 0.870 \\
\hline Breakfast & 1.230 & 0.517 & 0.018 & 0.595 & 0.346 & 0.086 & 0.349 & 0.220 & 0.113 & 0.448 & 0.134 & 0.001 \\
\hline \multicolumn{13}{|l|}{ Obesity } \\
\hline General obesity & 0.201 & 0.192 & 0.296 & 0.298 & 0.126 & 0.018 & 0.053 & 0.082 & 0.521 & -0.018 & 0.050 & 0.719 \\
\hline Abdominal obesity & $1.05 \mid$ & 0.177 & $<0.001$ & 0.398 & 0.118 & 0.001 & 0.356 & 0.075 & $<0.001$ & 0.244 & 0.046 & $<0.001$ \\
\hline Constant & -15.010 & 1.957 & $<0.001$ & -7.622 & 0.888 & $<0.001$ & -3.863 & 0.565 & $<0.001$ & -1.796 & 0.336 & $<0.001$ \\
\hline$R^{2}$ & 0.409 & & $<0.001$ & 0.297 & & $<0.001$ & 0.228 & & $<0.001$ & 0.437 & & $<0.001$ \\
\hline Adjusted $R^{2}$ & 0.401 & & $<0.001$ & 0.289 & & $<0.001$ & 0.218 & & $<0.001$ & 0.430 & & $<0.001$ \\
\hline
\end{tabular}

Esquinas et al. ${ }^{35}$ The concordance with this earlier study may be due to the use of the phenotype of frailty, which measures physical frailty. ${ }^{36}$ This phenotype consists of five domains, including weakness, slow walking speed, unintentional weight loss, exhaustion, and low physical activity; four of these criteria are also included in the TFI. However, a recent study suggested that the phenotype of frailty should be re-calibrated for people who are overweight and obese. ${ }^{37}$ According to Boutin and colleagues, overweight and obesity reduce the risk of adverse outcomes in community-dwelling older women (death, fall risk, hip fracture). By contrast, a systematic review reported a positive relationship between BMI and physical frailty. ${ }^{38}$ Thus, further studies of the association between general obesity or abdominal obesity and physical frailty are clearly needed.

We found that obesity was positively associated with physical frailty in older people with hypertension, a finding supported by a previous study. ${ }^{39}$ Physical frailty is closely and negatively associated with medication adherence and treatment adherence in older people with hypertension. ${ }^{11,40,41}$ Poor medication adherence and treatment adherence cause adverse outcomes such as hospitalization and disability. In turn, these adverse outcomes increase the prevalence of physical frailty. Second, in this study multidimensional frailty coexisted with hypertension in $46.5 \%$ of patients. Older people with hypertension who are either generally obese or 
abdominally obese have less muscle mass due to fat infiltration of the muscle and obesity-associated inactivity. ${ }^{42}$ Older people with hypertension who are abdominally obese also have a high level of insulin resistance, which may in turn increase the risk of frailty. ${ }^{43}$ Additionally, the ratio of fat mass to muscle mass or the amount of visceral versus peripheral fat may be strongly associated with frailty. Our study also demonstrated that abdominal obesity was associated with psychological frailty and social frailty. To the best of our knowledge, this is the first study to investigate the association between obesity and multidimensional frailty, so the results could not be compared with previous studies regarding psychological and social frailty. However, associations between individual components of psychological or social frailty and obesity were investigated in earlier studies. One five-year observational study showed that general obesity at baseline was associated with an increased risk of depression five years later. ${ }^{44}$ Another study showed that people who were obese had a higher risk of depression and anxiety. Depression and anxiety are closely associated with psychological frailty and social frailty. ${ }^{43}$ Besides the emerging evidence on obesity and frailty, the distinction between the association of abdominal obesity and frailty and the association of general obesity and frailty has been largely unexplored.

In addition to the findings discussed above, a higher multidimensional frailty risk was found in the alcohol abstention group compared to the alcohol consuming group. Similarly, a recent longitudinal study in older people reported a lower incidence of functional limitations associated with alcohol intake versus abstention. ${ }^{45}$ In addition, light-to-moderate alcohol consumption is reportedly protective against all-cause mortality and cardiovascular diseases. ${ }^{46}$ The present study also showed that older people who do not eat breakfast tend to be multidimensional frail. One explanation could be that people without an appetite for breakfast have less motivation in terms of functional exercise and social interaction. ${ }^{47}$ More detailed explanations should be explored in future studies. Our analyses also showed that the socio-demographic characteristics older age, gender (women), unmarried or without a partner, and high monthly income were associated with at least two of the four frailty variables. That unmarried or without a partner is associated with both multidimensional and social frailty is not surprising, because the TFI used for measuring multidimensional frailty includes living alone as a component of social frailty.

Some limitations of our study should be noted. First, most data were obtained by self-report, and recall errors may have resulted in some incorrect answers. Second, our data included possible confounders (e.g., regions, occupations), and we were not able to rule out all possible confounding factors. This means that there may be some unavoidable selection bias in our study. Future large-scale studies should expand classifications to reduce this limitation. Third, we only included individuals with hypertension, which limits the generalizability of our findings. Finally, the cross-sectional design of this study does not allow strict cause-effect interpretations of the associations between obesity and multidimensional frailty.

\section{Conclusion}

Age-related multidimensional frailty is a daily reality for community-dwelling older people with hypertension. This study showed that abdominal obesity (thus a larger WC) is closely associated with increased risk for multidimensional frailty, while general obesity (a higher BMI) is associated with physical frailty in older people with hypertension. A better understanding of the associations between obesity and multidimensional frailty may help improve the health and quality of life of older people living with hypertension.

\section{Abbreviations}

TFI, Tilburg Frailty Indicator; BMI, Body mass index; WC, Waist circumference.

\section{Ethics Approval and Informed Consent}

This study was approved by the Institutional Review Board of Zhengzhou University. Information was only collected after written consent was obtained from all participants. This study was conducted in accordance with the Declaration of Helsinki.

\section{Consent for Publication}

The authors obtained written informed consent to publish the participant's details.

\section{Acknowledgments}

We gratefully acknowledged the staff of the community health service centers in Hangdong community, Nanguan community and Qinling community for their kind assistance in data collection.

\section{Author Contributions}

All authors made substantial contributions to conception and design, acquisition of data, or analysis and interpretation of data; took part in drafting the article or revising it critically for important intellectual content; gave final approval of the version to be published; and agree to be accountable for all aspects of the work. 


\section{Funding}

This work was supported by the National Science Foundation of China grant (U1404814), and Henan Province Science, Technology Innovation Talent Support (17HASTIT048). This study was also funded by the China Scholarship Council.

\section{Disclosure}

The authors declare that they have no conflicts of interest.

\section{References}

1. Gilbert T, Neuburger J, Kraindler J, et al. Development and validation of a hospital frailty risk score focusing on older people in acute care settings using electronic hospital records: an observational study. Lancet. 2018;391(10132):1775-1782. doi:10.1016/S0140-6736(18)30668-8

2. Bos AJG. Aging and frailty or frailty and aging? Geriatr Gerontol Int. 2016;16(7):880. doi:10.1111/ggi.12596

3. Chen XJ, Mao GX, Leng SX. Frailty syndrome: an overview. Clin Interv Aging. 2014;9:433-441. doi:10.2147/CIA.S45300

4. Aprahamian I, Sassaki E, Dos Santos MF, et al. Hypertension and frailty in older adults. J Clin Hypertens. 2018;20(1):186-192. doi: $10.1111 /$ jch. 13135

5. Basile G, Catalano A, Mandraffino G, et al. Relationship between blood pressure and frailty in older hypertensive outpatients. Aging Clin Exp Res. 2017;29(5):1049-1053. doi:10.1007/s40520-016-0684-5

6. Gobbens RJ, Luijkx KG, Wijnen-Sponselee MT, Schols JM. In search of an integral conceptual definition of frailty: opinions of experts. J Am Med Dir Assoc. 2010;11(5):338-343. doi:10.1016/j. jamda.2009.09.015

7. Schuurmans H, Steverink N, Lindenberg S, Frieswijk N, Slaets JPJ. Old or frail: what tells us more? J Gerontol Series Biol Sci Med Sci. 2004;59(9):962-965. doi:10.1093/gerona/59.9.M962

8. Gobbens RJ, van Assen MA, Luijkx KG, Wijnen-Sponselee MT, Schols JM. The tilburg frailty indicator: psychometric properties. $J \mathrm{Am}$ Med Dir Assoc. 2010;11(5):344-355. doi:10.1016/j.jamda.2009.11.003

9. Torlasco C, Faini A, Makil E, et al. Cardiovascular risk and hypertension control in Italy. data from the 2015 world hypertension day. Int J Cardiol. 2017;243:529-532. doi:10.1016/j.ijcard.2017.03.151

10. Su P, Ding H, Zhang W, et al. Joint association of obesity and hypertension with disability in the elderly- a community-based study of residents in Shanghai, China. J Nutr Health Aging. 2017;21(4):362-369. doi:10.1007/s12603-016-0777-z

11. Walston J, McBurnie MA, Newman A, et al. Frailty and activation of the inflammation and coagulation systems with and without clinical comorbidities: results from the cardiovascular health study. Arch Intern Med. 2002;162(20):2333-2341. doi:10.1001/ archinte.162.20.2333

12. Bagshaw SM, Stelfox HT, Johnson JA, et al. Long-term association between frailty and health-related quality of life among survivors of critical illness: a prospective multicenter cohort study. Crit Care Med. 2015;43(5):973-982. doi:10.1097/CCM.0000000000000860

13. Gobbens RJ, van Assen MA. The prediction of quality of life by physical, psychological and social components of frailty in community-dwelling older people. Qual Life Res. 2014;23 (8):2289-2300. doi:10.1007/s11136-014-0672-1

14. Zamboni M, Mazzali G, Zoico E, et al. Health consequences of obesity in the elderly: a review of four unresolved questions. Int J Obes. 2005;29(9):1011-1029. doi:10.1038/sj.ijo.0803005

15. Hubbard RE, Lang IA, Llewellyn DJ, Rockwood K. Frailty, body mass index, and abdominal obesity in older people. J Gerontol Series Biol Sci Med Sci. 2010;65(4):377-381. doi:10.1093/gerona/glp186
16. Kalish VB. Obesity in older adults. Prim Care. 2016;43(1):137-144. doi:10.1016/j.pop.2015.10.002

17. Oreopoulos A, Kalantar-Zadeh K, Sharma AM, Fonarow GC. The obesity paradox in the elderly: potential mechanisms and clinical implications. Clin Geriatr Med. 2009;25(4):643-+. doi:10.1016/j. cger.2009.07.005

18. Goisser S, Kemmler W, Porzel S, et al. Sarcopenic obesity and complex interventions with nutrition and exercise in community-dwelling older persons - a narrative review. Clin Interv Aging. 2015;10.

19. Crow RS, Lohman MC, Titus AJ, et al. Association of obesity and frailty in older adults: NHANES 1999-2004. J Nut Heal Aging. 2019;23(2):138-144. doi:10.1007/s12603-018-1138-x

20. Mezuk B, Lohman MC, Rock AK, Payne ME. Trajectories of body mass indices and development of frailty: evidence from the health and retirement study. Obesity. 2016;24(8):1643-1647. doi:10.1002/ oby. 21572

21. Blaum CS, Xue QL, Michelon E, Semba RD, Fried LP. The association between obesity and the frailty syndrome in older women: the women's health and aging studies. J Am Geriatr Soc. 2005;53 (6):927-934. doi:10.1111/j.1532-5415.2005.53300.x

22. Jeoung BJ, Lee YCA. Study of relationship between frailty and physical performance in elderly women. $J$ Exercise Rehabil. 2015;11(4):215-219. doi:10.12965/jer.150223

23. Tucker JM, Tucker LA, Lecheminant J, Bailey B. Obesity increases risk of declining physical activity over time in women: a prospective cohort study. Obesity. 2013;21(12):E715-E720. doi:10.1002/ oby. 20415

24. Scott KM, Bruffaerts R, Simon GE, et al. Obesity and mental disorders in the general population: results from the world mental health surveys. Int J Obes. 2008;32(1):192-200. doi:10.1038/sj.ijo.0803701

25. Chang HH, Yen ST. Association between obesity and depression: evidence from a longitudinal sample of the elderly in Taiwan. Aging Ment Health. 2012;16(2):173-180. doi:10.1080/ 13607863.2011.605053

26. Dixon JB. The effect of obesity on health outcomes. Mol Cell Endocrinol. 2010;316(2):104-108. doi:10.1016/j.mce.2009.07.008

27. Kam ACS, Leung EKS, Chan PYB, Tong MCF. Cross-cultural adaptation and psychometric properties of the Chinese tinnitus functional index. Int $J$ Audiol. 2018;57(2):91-97. doi:10.1080/ 14992027.2017.1375162

28. Pan WH, Yeh WT. How to define obesity? Evidence-based multiple action points for public awareness, screening, and treatment: an extension of Asian-Pacific recommendations. Asia Pac J Clin Nutr. 2008;17(3):370-374.

29. Anuurad E, Shiwaku K, Nogi A, et al. The new BMI criteria for asians by the regional office for the western pacific region of WHO are suitable for screening of overweight to prevent metabolic syndrome in elder Japanese workers. J Occup Health. 2003;45 (6):335-343. doi:10.1539/joh.45.335

30. Alberti KG, Zimmet P, Shaw J. The metabolic syndrome-a new worldwide definition. Lancet. 2005;366(9491):1059-1062. doi:10.1016/S0140-6736(05)67402-8

31. Wang Y, Mi J, Shan XY, Wang QJ, Ge KY. Is China facing an obesity epidemic and the consequences? The trends in obesity and chronic disease in China. Int $J$ Obes. 2007;31(1):177-188. doi:10.1038/sj. ijo.0803354

32. Dong L, Liu N, Tian X, et al. Reliability and validity of the Tilburg Frailty Indicator (TFI) among Chinese community-dwelling older people. Arch Gerontol Geriatr. 2017;73:21-28. doi:10.1016/j. archger.2017.07.001

33. Biritwum RB, Minicuci N, Yawson AE, et al. Prevalence of and factors associated with frailty and disability in older adults from China, Ghana, India, Mexico, Russia and South Africa. Maturitas. 2016;91:8-18. doi:10.1016/j.maturitas.2016.05.012 
34. Hoogendijk EO, van Hout HP, Heymans MW, et al. Explaining the association between educational level and frailty in older adults: results from a 13-year longitudinal study in the Netherlands. Ann Epidemiol. 2014;24(7):538-544.e532. doi:10.1016/j.annepidem.2014.05.002

35. Garcia-Esquinas E, Jose Garcia-Garcia F, Leon-Munoz LM, et al. Obesity, fat distribution, and risk of frailty in two population-based cohorts of older adults in Spain. Obesity. 2015;23(4):847-855. doi:10.1002/oby.21013

36. Fried LP, Tangen CM, Walston J, et al. Frailty in older adults: evidence for a phenotype. J Gerontol Series Biol Sci Med Sci. 2001;56(3):M146-M156. doi:10.1093/gerona/56.3.M146

37. Boutin E, Natella PA, Schott AM, et al. Interrelations between body mass index, frailty, and clinical adverse events in older community-dwelling women: the EPIDOS cohort study. Clin nut. 2018;37(5):1638-1644. doi:10.1016/j.clnu.2017.07.023

38. Feng Z, Lugtenberg M, Franse C, et al. Risk factors and protective factors associated with incident or increase of frailty among community-dwelling older adults: a systematic review of longitudinal studies. PLoS One. 2017;12(6):e0178383. doi:10.1371/journal.pone.0178383

39. Villareal DT, Apovian CM, Kushner RF, Klein S. Obesity in older adults: technical review and position statement of the American society for nutrition and NAASO, the obesity society. Am J Clin Nutr. 2005;82(5):923-934. doi:10.1093/ajen/82.5.923

40. Chudiak A, Jankowska-Polanska B, Uchmanowicz I. Effect of frailty syndrome on treatment compliance in older hypertensive patients. Clin Interv Aging. 2017;12:805-814. doi:10.2147/CIA.S126526

41. Jankowska-Polanska B, Dudek K, Szymanska-Chabowska A, Uchmanowicz I. The influence of frailty syndrome on medication adherence among elderly patients with hypertension. Clin Interv Aging. 2016;11:1781-1790. doi:10.2147/CIA.S113994
42. Cooper R, Hardy R, Bann D, et al. Body mass index from age 15 years onwards and muscle mass, strength, and quality in early old age: findings from the MRC national survey of health and development. J Gerontol a Biol Sci Med Sci. 2014;69 (10):1253-1259. doi:10.1093/gerona/glu039

43. Mlynarska A, Mlynarski R, Golba KS. Anxiety, age, education and activities of daily living as predictive factors of the occurrence of frailty syndrome in patients with heart rhythm disorders. Aging Ment Health. 2018;22(9):1179-1183. doi:10.1080/13607863.2017.1348468

44. Roberts RE, Deleger S, Strawbridge WJ, Kaplan GA. Prospective association between obesity and depression: evidence from the alameda county study. Int $J$ Obes. 2003;27(4):514-521. doi:10.1038/sj. ijo.0802204

45. Kojima G, Jivraj S, Iliffe S, Falcaro M, Liljas A, Walters K. Alcohol consumption and risk of incident frailty: the english longitudinal study of aging. J Am Med Dir Assoc. 2019;20(6):725-729. doi:10.1016/j.jamda.2018.10.011

46. Kojima G, Liljas A, Iliffe S, Jivraj S, Walters K. A systematic review and meta-analysis of prospective associations between alcohol consumption and incident frailty. Age Ageing. 2018;47(1):26-34. doi:10.1093/ageing/afx086

47. Prat MS, Fernandez X, Ribo L, Palomera E, Papiol M, Serra P. Loss of appetite in elderly people in the community and its relationship with functional capacity. Med Clin. 2008;130(14):531-533. doi: $10.1157 / 13119715$
Clinical Interventions in Aging

\section{Publish your work in this journal}

Clinical Interventions in Aging is an international, peer-reviewed journal focusing on evidence-based reports on the value or lack thereof of treatments intended to prevent or delay the onset of maladaptive correlates of aging in human beings. This journal is indexed on PubMed Central, MedLine, CAS, Scopus and the Elsevier

\section{Dovepress}

Bibliographic databases. The manuscript management system is completely online and includes a very quick and fair peer-review system, which is all easy to use. Visit http://www.dovepress.com/ testimonials.php to read real quotes from published authors. 